\title{
Vectorology and Factor Delivery in Induced Pluripotent Stem Cell Reprogramming
}

\author{
Kejin $\mathrm{Hu}$
}

Induced pluripotent stem cell (iPSC) reprogramming requires sustained expression of multiple reprogramming factors for a limited period of time (10-30 days). Conventional iPSC reprogramming was achieved using lentiviral or simple retroviral vectors. Retroviral reprogramming has flaws of insertional mutagenesis, uncontrolled silencing, residual expression and re-activation of transgenes, and immunogenicity. To overcome these issues, various technologies were explored, including adenoviral vectors, protein transduction, RNA transfection, minicircle DNA, excisable PiggyBac (PB) transposon, Cre-lox excision system, negative-sense RNA replicon, positive-sense RNA replicon, Epstein-Barr virus-based episomal plasmids, and repeated transfections of plasmids. This review provides summaries of the main vectorologies and factor delivery systems used in current reprogramming protocols.

\section{Introduction}

I NDUCED PLURIPOTENT STEM CELL (iPSC) reprogrammIng (or factor reprogramming) is a technology used to convert differentiated somatic cells back to embryonic-stemlike cells via the ectopic expression of multiple transcription factors (usually four transcription factors) [1,2]. iPSC reprogramming is a long process, taking 10-30 days to complete. Such a long process and the requirement for multiple factors pose challenges to factor delivery. The major application of iPSCs is autologous cell therapy. However, conventional iPSC reprogramming employs integrating viral vectors (lentiviral and gamma retroviral) for delivery of reprogramming factors into reprogramming cells. Transgene integration has a risk of insertional mutagenesis [3]. In addition, the integrated reprogramming factors have residual expression in the established iPSC lines, which compromises the quality of iPSCs. The integrated reprogramming factors could be activated at any stage of differentiation and/or after transplantation of the iPSC-derived cells. This can be detrimental since all of the reprogramming factors are oncogenic to some extent with MYC as the strongest oncogene. Factor reprogramming also suffers from low efficiency and slow kinetics. Uncontrolled silencing of retroviral vectors (RVs) also compromises reprogramming efficiency and quality. Ever since the establishment of iPSC technology, great efforts have been invested in developing new approaches to address the various issues mentioned previously [4-6]. To achieve these goals, many distinct technologies are employed in current reprogramming protocols. These include nonintegrating adenoviral vectors [7], excisable PiggyBac (PB) transposon [8], excision of transgenes with the Cre-Lox system upon completion of reprogramming $[9,10]$, repeated transfection with conventional plasmids [11], minicircle DNA [12], Epstein-Barr virus-based replicating episomal plasmids [4-6], protein transduction [13], mRNA transfection [14], negative-sense RNA vectors (Sendai viral vector) [15], positive-sense RNA vector/replicons [16], and the use of polycistrons mediated by $2 \mathrm{~A}$ peptide $[9,11]$, and/or Internal Ribosome Entry Site (IRES) [4]. This review summarizes information relative to vector designs and factor delivery systems used in current reprogramming protocols. It is expected to be a supporting companion to the major survey of iPSC technologies in the same issue [17].

\section{Retroviral Vectors}

The so-called RV widely used in reprogramming and gene transfer/therapy is based on the simple gamma retrovirus of murine origin, largely the Moloney murine leukemia virus $(\mathrm{M}-\mathrm{MuLV})[1,18-20]$. The gamma RV $(\gamma-\mathrm{RV})$ played a critical role in the development of iPSC technology due to its ability to provide relatively long-term transgene expression [1]. Retrovirus has an RNA genome that can be converted into a double-stranded DNA by its own reverse transcriptase. The DNA is subsequently integrated into the host genome to generate a heritable DNA provirus. The process of heritability includes the production of RNA genomes via transcription of the provirus DNA, packaging of RNA genomes into viral particles, infection via interaction 
between the viral envelope proteins and viral receptors on host cells, reverse transcription, generation of a doublestranded DNA, and finally its subsequent integration back into the host genome as a provirus [21]. The simple gamma retrovirus encodes only three genes: gag, pol, and env. During virion maturation, Gag protein is cleaved into matrix (MA), p12, capsid (CA), and nucleocapsid (NC) by the viral protease (PR). The Pol moiety of Gag-Pol is also cleaved to release free $\mathrm{PR}$, reverse transcriptase (RT), and integrase (IN) [21,22]. An advanced replication-incompetent RV can be constructed with only the essential cis-acting elements, including the packaging signal, primer binding sequence (PBS), polypurine tract (PPT), and long terminal repeats (LTRs), but devoid of all of the viral protein-coding genes. Transgenes are inserted in place of the deleted viral structural genes. However, the viral structural proteins have to be provided in trans for efficient encapsidation, infection/ transduction, reverse transcription, and integration. The transgenes integrated into the host genome are then transcribed and translated by the cellular machinery. The infectability of viral particles depends largely on the interaction of the viral envelope protein and the viral receptor on host cells [23,24]. We can change the vector tropism by pseudotyping the same RV system with different envelope proteins, and murine virus-based RVs can be ecotropic, amphotropic, or pantropic (or polytropic) depending on the envelope proteins used. Ecotropic vehicles transduce only rodent cells due to the strict requirement for the rodent ecotropic viral receptor mCAT1 (cationic amino acid transporter), but cannot transduce human cells although human cells do express an mCAT1 homolog that is $87 \%$ identical to the mouse counterpart [23,24]. With the sodiumdependent phosphate symporter (Ram1) as a viral receptor, amphotropic vehicles transduce cells of rodent, human, chicken, dog, cat, and mink. Pantropic vectors transduce an even wider range of cells. The widely used pantropic vectors are pseudotyped with the vesicular stomatitis virus $\mathrm{G}$ protein (VSV-G). The VSV-G-pseudotyped virus enters cells through interaction with some mysterious ubiquitous cell membrane components [25], and thus is able to infect/ transduce a wide variety of cell types, including cells of insects, fish, frogs, and humans. Recently, this ubiquitous VSV-G receptor was identified as the low-density lipoprotein receptor (LDLR) [26]. VSV-G pseudotyping not only broadens the tropism, but also increases the stability of viral particles and makes it possible to concentrate viral particles by ultracentrifugation [25]. Ecotropic and amphotropic retroviral particles are usually prepared using a packaging cell line that stably expresses the viral structural proteins Gag, Pol, and Env [27], but for pantropic virus, packaging is realized by transient cotransfection of the env gene and a transfer plasmid because of the cytotoxicity of VSV-G $[25,28]$. Like the wild-type retrovirus, M-MuLV-based RVs transduce only dividing cells $[29,30]$, limiting their use in delivering reprogramming factors into nondividing and slow-dividing cells. Transgenes delivered by RVs are permanently integrated into host genomes, and thus provide stable expression of transgenes. Transgenes can be silenced depending on locations of integration (position effect), cell types, promoters installed, and viral cis-acting sequences. In embryonic stem cells (ESCs) and iPSCs, TRIM28/ZFP809 complex silences RV by binding to the viral PBS site, but not the HIV1-based lentiviral vectors [31,32]. Positional vector silencing in RVs and LVs may be alleviated by the incorporation of two classes of transcriptional regulatory elements: elements with boundary function, such as insulators and scaffold/matrix attachment regions, and elements that possess a dominant chromatin remodeling and transcriptional activating capacity, such as locus control regions and ubiquitous chromatin opening elements [33]. However, addition of these sequences impedes virus production because these elements are usually long. In addition, timely silencing might be beneficial to reprogramming [34], and transgene silencing provides a useful marker for complete reprogramming [35], although premature silencing is detrimental to reprogramming. Therefore, the best vector design to facilitate complete reprogramming should provide for relative longterm expression, while also allowing for timely silencing of the reprogramming factors.

\section{HIV1-Based Lentiviral Vector}

Lentiviral vectors were utilized to establish the first human iPSC line [2]. Lentiviral vectors have been developed from various viruses, including the equine infectious anemia virus (EIVA), bovine leukemia virus, simian immunodeficiency virus (SIV), feline immunodeficiency virus (FIV), foamy virus, and HIV2, but the most well-developed and widely used lentiviral vectors are based on HIV1 [36-39]. Like other lentiviruses, HIV1 is a complex retrovirus because it encodes additional regulatory (Tat and Rev) and accessory proteins (Vpr, Vpu, Vif, and Nef) in addition to the common Gag, Pol, and Env proteins shared with simple retroviruses [40]. Development of lentiviral vectors is facilitated by knowledge of simple RVs. HIV1 vectors are constructed with HIV1 cis-acting sequences, including LTR sequences, packaging signal, PBS, central PPT, and Rev response element (Fig. 1). A non-HIV1 sequence, WPRE (woodchuck hepatitis virus post-transcriptional regulatory element), is usually included to increase transgene expression (Fig. 1). One major goal in LV development is to increase safety since HIV1 causes human disease, and this is achieved by the following approaches: (1) deleting all of the viral-encoding genes from the transfer vector; (2) deleting some viral regulatory sequences in transfer vector, especially the enhancer and promoter in the U3 region of the $3^{\prime}$ LTR to make the vector replication incompetent (selfinactivating vector or SIN vector); (3) providing the essential viral proteins in trans from separate plasmids (split-genome approach); and (4) removing the packaging signal from the packaging plasmids; and (5) include nonviral heterologous promoters in the packaging plasmids [41]. Unlike RVs, HIV1 vectors require at least one regulatory viral protein, that is, Rev, in addition to Gag, Pol, and Env. HIV1 infects only a few types of cells ( $\mathrm{T}$ cells, macrophages, and monocytes), and therefore the HIV1-based vectors with native envelopes have a very narrow tropism. Vector tropism can be broadened by pseudotyping with envelope proteins from various viruses, such as M-MuLV ecotropic and amphotropic Env glycoproteins, but the titer is generally low with these Env [37]. VSV-G can also pseudotype HIV1-based vectors, and gives the highest titer. The HIV1-based lentiviral vectors are usually packaged by transient cotransfection of all plasmids (transfer plasmids, packaging plasmids, 


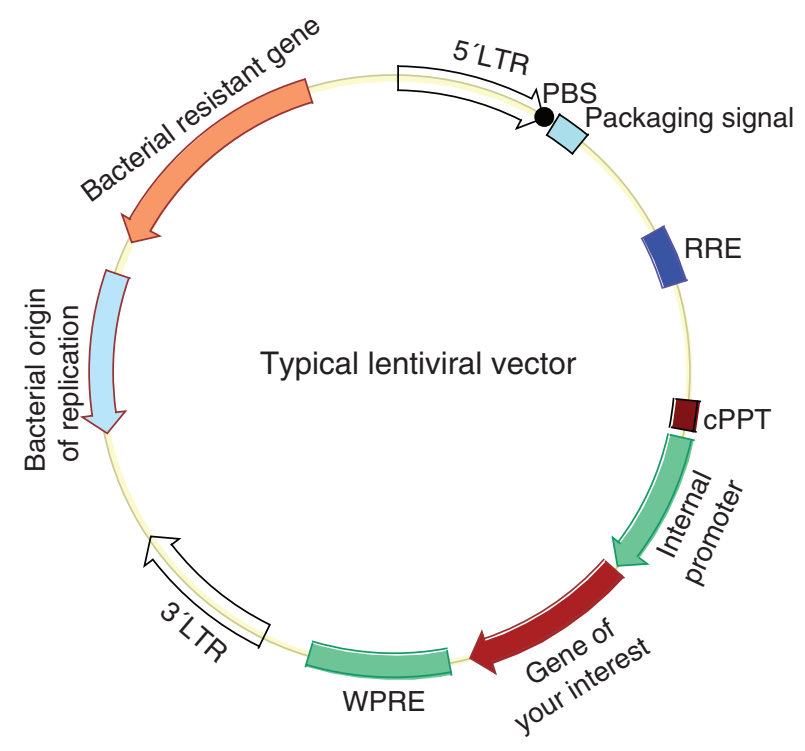

FIG. 1. Schematic map of the transfer plasmid of lentiviral vector. cPPT, central polypurine tract (dark purple box); LTR, long terminal repeat (large open arrows); PBS, primer binding sequence (black dot); RRE, rev response element (blue box); WPRE, Woodchuck hepatitis virus post-transcriptional regulatory element (cyan box). Other major components are annotated in the figure. Figure is not drawn to proportion. Color images available online at www.liebertpub.com/scd

and envelope plasmids) due to the toxic nature of some of the HIV1 proteins and VSV-G [42]. Inducible controlled expression of the viral packaging proteins makes it possible to package lentiviral vectors with a packaging cell line, but this method is not in wide use due to low titer and leaky expression of the toxic VSV-G and Rev [37,43,44]. In contrast to simple RVs, HIV1-based vectors can transduce nondividing and slow-dividing cells [45]. This is advantageous considering that somatic stem cells are better starting cells for reprogramming [3], but are generally slow growing or in quiescent states [46].

\section{Minicircle DNA}

Minicircle vectors were used to establish footprint-free iPSC lines because of their episomal nature and low degree of vector silencing [12]. Minicircle refers to episomal supercoiled circular DNA with only mammalian expression cassette and devoid of the bacterial backbone (Fig. 2). Bacterial DNA sequences (origin of replication, resistant gene, and others) in a mammalian expression construct are found to be largely responsible for the dramatic silencing of the delivered transgenes [47], and therefore systems have been developed to generate circular DNA (minicircle) containing the mammalian expression cassette only, and devoid of the bacterial backbone, using controlled, inducible intramolecular site-specific recombination in bacterial hosts prior to harvest of minicircles from bacterial cultures [48]. Central to these technologies is intramolecular site-specific recombination. Intramolecular recombination can be realized via different recombinases, including Streptomyces phage integrase $Ф C 31[48,49]$, the Cre recombinase from bacteriophage $P 1$ [50], FLP recombinase from the yeast plasmid $2 \mu \mathrm{m}$ circle [51], and the ParA resolvase from the multimer resolution system of the broad host-range plasmid RK2 or RP4 [52]. The resulting minicircles can be purified by cesium gradient centrifugation after the selective destruction of bacterial backbone plasmids (miniplasmid) and of the residual parental plasmids by enzymatic restriction. This enzymatic removal of miniplasmids and residual parental plasmids is costly and labor intensive. Recently, a simple system was developed in which the miniplasmids and parental plasmids can be destroyed in vivo shortly after recombination by incorporating tandem repeats of the recognition sequence for yeast $I$ SceI outside of the recombination sites, in a genetically modified Escherichia coli strain that harbors inducible I-SceI genes and ФC31 integrase (Fig. 2). This leaves only minicircles in the host cells, and allows for their simple purification using standard maxipreps or minipreps [49] (Fig. 2). Minicircles can also be purified using proteinDNA interaction chromatography [52]. Minicircles are generally nonreplicating, but a replicating minicircle was reported [51].

\section{Protein Transduction}

Protein transduction is a technology to deliver exogenous proteins into cells in culture or directly into tissues of living organisms [53-57]. Owing to their apparent lack of genome integration property, these technologies were used to generate footprint-free iPSCs $[13,58]$. Delivery of proteins into cells encounters a great barrier, the hydrophobic cellular membrane. The most widely used method is transduction mediated by a protein transduction domain (PTD; also called cell-penetrating peptide, CPP). PTD occurs naturally in many proteins, such as the HIV1 transcriptional activator TAT [59-61], the structural protein VP22 of herpes simplex virus type 1 [62], and the Drosophila transcription factor antennapedia (AntP) [63,64]. These PTDs are fused onto proteins of interest for transduction. The mechanism of PTDmediated transduction is poorly understood, but it might involve interaction between PTD and the cell membrane, endocytosis, and retrograde transportation into the cytoplasm and nucleus [54]. PTD is a highly basic domain containing a large portion of arginines, so the positively charged PTD can interact with the negatively charged components of the cell membrane via electrostatic interaction. Further internalization of the PTD involves different endocytotic pathways (macropinocytosis, clathrin-mediated endocytosis, and caveolin-mediated endocytosis) although previous data suggested that this process is independent of endocytosis, energy, and specific receptors $[65,66]$. PTD-mediated protein transduction can occur in many different cell types, including hard-to-transfect cells such as neural cells [63], and it delivers large proteins into all tissues in live animals including brain indicative of an ability to cross the blood-brain barrier [67]. One drawback is the short half-life of the transduced protein in cells. It is found that poly-arginine (around eight arginines) transduced the tagged proteins more efficiently than the naturally occurring PTDs [68]. PTD-mediated transduction is fast. In contrast to other delivery systems such as virus-mediated gene delivery, PTD-mediated protein transduction is not toxic to cells [61,68]. PTD not only delivers protein, it can also deliver DNA, RNA, nanoparticles, 
FIG. 2. Minicircle generation system. Producer plasmid undergoes intramolecular recombination in an Escherichia coli strain that harbors the inducible $\Phi C 31$ and the rare-cut I-Sce I genes. The resulting miniplasmid of bacterial backbone is degraded by $I$-SceI-initiated digestion of DNA since this plasmid contains 32 copies of I-SceI recognition sequences. The second recombination product, the minicircle DNA, remains intact in the bacterial host, and can simply be purified using standard maxiprep or miniprep. attB, bacterial attachment (green star); attP, phage attachment (ochre red star). Color images available online at www.liebertpub.com/scd

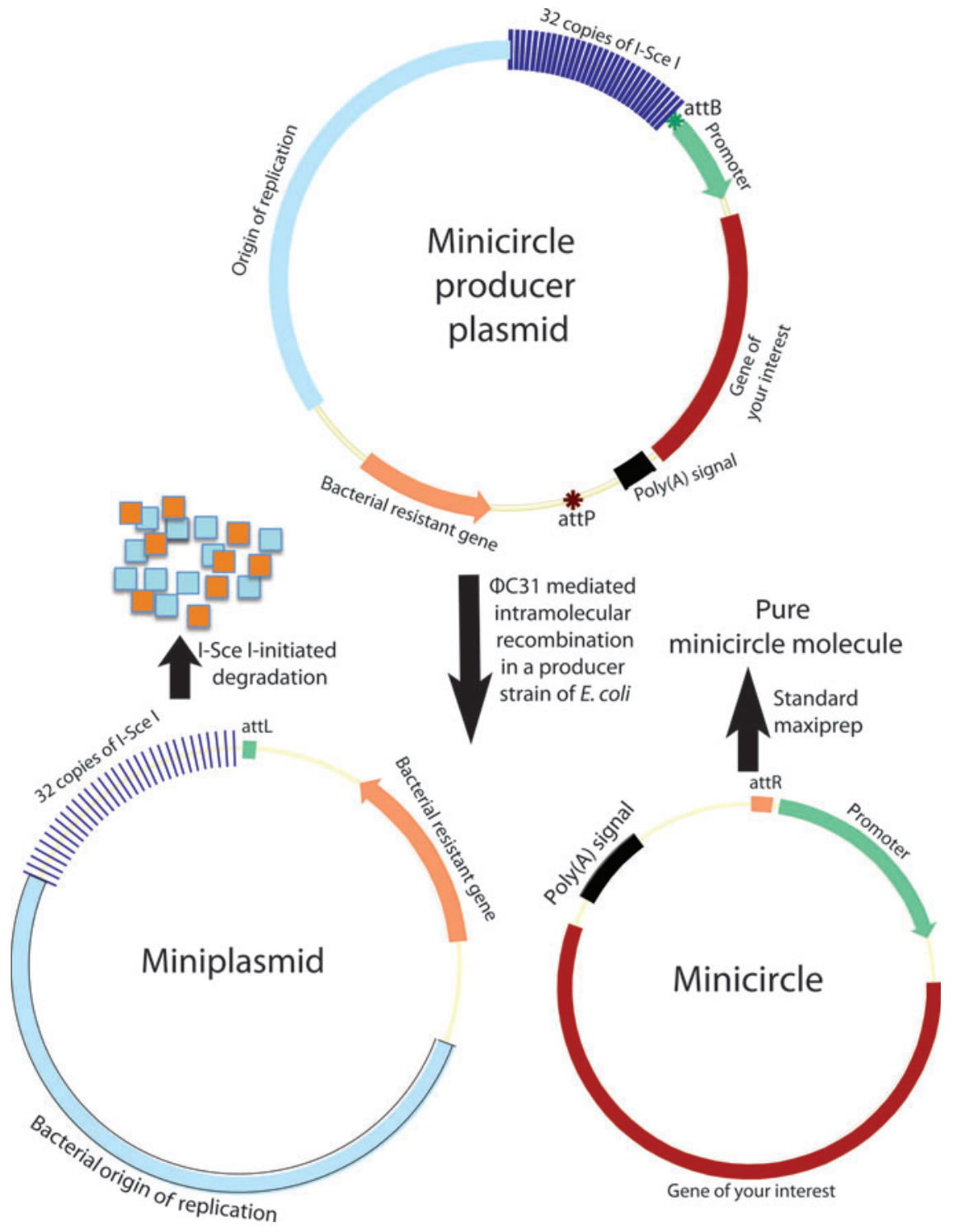

liposomes, fluorescence probes, and drugs [57]. PTD has a large cargo capacity and can deliver protein $>100 \mathrm{kDa}$ [67].

PTD-mediated protein transduction is an active process. Proteins can also be delivered passively into living cells by diffusion through the cell membrane temporarily opened using mechanical approaches or membrane-permeabilizing agents. One example of mechanical approaches is scrape loading [59]. The commonly used membrane permeabilizing agent is streptolysin $\mathrm{O}$, which is a cholesterol-binding, thiolactivated, calcium-sensitive bacterial exotoxin that stimulates the formation of pores in the plasma membrane of mammalian cells up to the size of $35 \mathrm{~nm}$ that is large enough for large proteins to traverse but too small for organelles to escape [69-71]. When permeabilizing conditions are optimized, the process is reversible under optimal re-sealing conditions, and the treated cells will remain viable and normal [70]. In one protein reprogramming experiment, the reprogramming factors in ESC extracts were delivered into the reprogramming cells temporarily permeabilized using streptolysin O [71].

\section{Sendai Viral Vectors}

Sendai virus is an enveloped, nonsegmented, singlestranded, negative-sense RNA virus of the Paramyxoviridae family [72]. The RNA viral genome is 15,384 nucleotides, which consists of six independent cistrons ( $N P, P / C / N, M, F$, $H N$, and $L$ ) encoding six essential proteins-nucleoprotein $(\mathrm{NP})$, phosphoprotein $(\mathrm{P})$, matrix protein $(\mathrm{M})$, fusion protein $(\mathrm{F})$, hemagglutinin-neuraminidase $(\mathrm{HN})$, and large protein $(\mathrm{L}$, the catalytic subunit of the RNA-dependent RNA polymerase) - and two accessory proteins, $\mathrm{C}$ and $\mathrm{V}$ proteins. $\mathrm{L}$ is believed to possess all of the enzymatic activities necessary for viral transcription and replication. Genomic RNA, NP, P, and $\mathrm{L}$ form the ribonucleoprotein (RNP) that is a minimal functional unit in terms of genome replication and viral mRNA transcription after entering host cells. Unlike retroviruses, Sendai virus has no DNA phase, and therefore generally does not integrate into host genomes. This property has been employed to produce iPSC lines free of transgene footprints [15]. Replication and transcription are completed in 
the host cytoplasm and need no host nuclear factors. The only cis-element required for gene transcription is a short genestart signal (UCCCNNUUUC) before each cistron, and a short gene-end signal (AUUCUUUUU) at the end of each cistron. Like their parent viruses, $\mathrm{SeV}$ vectors (SeVVs) in the form of RNP replicate and transcribe in the cytoplasm of host cells, without going through a DNA phase. This ability of RNP replication in the transduced cells ensures lasting expression of the reprogramming factors for complete reprogramming. The first-generation SeVV contains the entire viral genome with foreign genes inserted into seven possible locations, and is therefore an infectious vector [73,74]. The second generation of vectors deletes one of the three envelope-related genes to make the vector incompetent and less immunogenic [73]. Most advanced vectors delete all of the three envelope genes and modify the remaining genes and sequences $[75,76]$. The $F$-deficient nontransmissible vector (SeVV/ $\Delta F$ ) was developed by deleting the envelope fusion gene ( $F$ gene) from the RNA genome [77]. The F protein is provided in trans from a packaging cell line. Such an $F$ deficient vector cannot form intact infectious viral particles, yet can replicate and transcribe in the cytoplasm of host cells, so as to provide persistent transgene expression. But $F$-deficient vectors can generate significant amounts of virus-like particles, and such virus-like particles have residual infection activity [76]. For enhanced safety, formation of virus-like particles from the transfected host cells was significantly reduced by introducing temperature-sensitive mutations into the two remaining envelope-related genes $M$ and $H N$ in the context of $\Delta F$ (SeVV/M $M^{t s} H N^{t s} \Delta F$ vector) [78]. The most advanced SeVV incapable of forming any viral particles was developed by deleting all three of the structural genes $(M, F$, and $H N$ ) from the viral genome [75]. The efficiency of this triple-deficient vector is enhanced by incorporating missense mutations in the $P$ and $L$ genes, and by introduction of geneend signal before $N P$ gene, which enable a stable gene expression and avoid IFN $\beta$ induction (SeVV/ $\triangle M \Delta F \Delta H N$ vector) [76]. SeVV/ $\triangle M \triangle F \Delta H N$ virion particles are packaged in a cell line expressing $M, F$, and $H N$. Like Sendai virus, SeVV/ $\triangle M \triangle F \triangle H N$ vectors transduce a wide range of cells from avian to human because $\mathrm{SeVV}$ recognizes ubiquitous sialic acids as its primary receptor. Three exogenous genes can be installed in place of $M, F$, and $H N$. Additional transgenes can be incorporated by the introduction of gene-start and gene-end signals. Therefore, in the SeVV/ $\Delta M \Delta F \Delta H N$ vector, all of the four reprogramming factors can be installed on a single vector [76], while with the $S e V / \Delta F$ vector, four individual viruses are needed to deliver the four reprogramming factors [79]. Viral replication relies on an RNAdependent RNA polymerase, and therefore siRNA against the $L$ gene can actively clear viral replicons from transduced cells when there is no longer a need for transgene expression following the completion of reprogramming [76]. After reprogramming, viral replicons can also be cleared by a short temperature shift if $t s$ mutations are introduced into the viral RNA polymerase gene of the vector [79]. Viral replicons become diluted over cell divisions, and some iPSCs eventually become devoid of viral replicons after sequential passaging, and so cells free of viral replicons can be passively obtained by negative selection against viruscontaining iPSCs using an antibody against the spike protein $\mathrm{HN}$ when the $H N$ gene is included in the vector [80].

\section{RNA Transfection}

RNA can be directly delivered into cultured cells or animals as an alternative to DNA and protein $[81,82]$. In contrast to DNA delivery, the destination of mRNA is the cytoplasm rather than the nucleus, and more genetic information can reach the target sites quicker due to reduced barriers during transfection because the inefficient nuclear internalization of transgenes is eliminated, and a shorter transport in cytoplasm will be needed [83]. mRNA can be translated almost instantly while DNA needs an additional transcription step. Expression of genes delivered in the form of DNA is frequently silenced by epigenetic modification while that of RNA is not. RNA does not modify the host genome while DNA frequently does, and therefore RNAbased therapy is classified as a nongene therapy approach [84]. It is this feature of nongenome modification that makes synthetic mRNA appealing in the establishment of footprintfree iPSC lines. However, mRNA transfection has two major drawbacks. First, the half-life of RNA is short and the expression of the delivered mRNA is more transient compared to that of the delivered DNA, limiting its use in a long process like reprogramming. Second, RNAs are more immunogenic than DNA, and cause strong innate immune responses through the antiviral mechanisms of the host cells, thus introducing complications in reprogramming. Modifications of synthetic mRNA can substantially reduce immune responses from transfected cells [14,81], and are essential for efficient transgene expression and reprogramming [85]. A combination of modifications to mRNAs allows for robust expression of the transfected mRNAs. Essential or beneficial modifications include inclusion of $5^{\prime}$ - and $3^{\prime}$-UTRs of $\beta$ globin, addition of a poly(A) tail, capping with the antireverse cap analog, dephosphorylation of the uncapped population of the synthesized mRNAs, and incorporation of modified ribonucleoside bases such as pseudouridine [81,82]. Even with these modifications, reprogramming with synthetic mRNAs is not an easy task.

\section{Epstein-Barr Virus Episomal Vectors}

The Epstein-Barr virus (EBV) episomal vector used widely in reprogramming is an Epstein-Barr virus-based plasmid that can replicate and partition extrachromosomally in primate cells [86-88]. The ability to replicate in cells allows its use in a long process as reprogramming [4]. EBV vectors require only two components of viral origin, the ciselement OriP and the trans-acting factor EBNA1 [89,90]. EBNA1 encodes the Epstein-Barr virus nuclear antigen 1 (EBNA1). OriP is a $1.7-\mathrm{kb}$ DNA region containing two essential cis-acting sequences for plasmid replication and retention, namely, the family of repeat (FR), and the region of dyad symmetry (DS; also named origin of bidirectional DNA replication, OBR) [91]. FR functions to maintain the plasmids, and consists of 20 tandem imperfect copies of a 30-bp repeating unit, each of which contains an EBNA1 binding site. FR is also an EBNA1-dependent transcription enhancer. DS is a plasmid replicator, and contains four EBNA1 binding sites [92]. EBNA1 binds to both FR and DS for proper plasmid replication and retention. EBV plasmids rely on host for replication and retention because EBNA1 does not have any enzyme activity except for DNA binding 
FIG. 3. Coexpression mediated by $2 \mathrm{~A}$ peptide and IRES. Upper panel: 2A-mediated coexpression of four genes into four individual proteins from a single ORF. $U p$ per part is the eukaryotic expression cassette; middle is the resulting mRNA, and the bottom is the resulting four individual proteins. Lower panel: IRES-mediated coexpression of two genes into two individual proteins from two separate ORFs of the same mRNA. ORF, open reading frame. Color images available online at www .liebertpub.com/scd

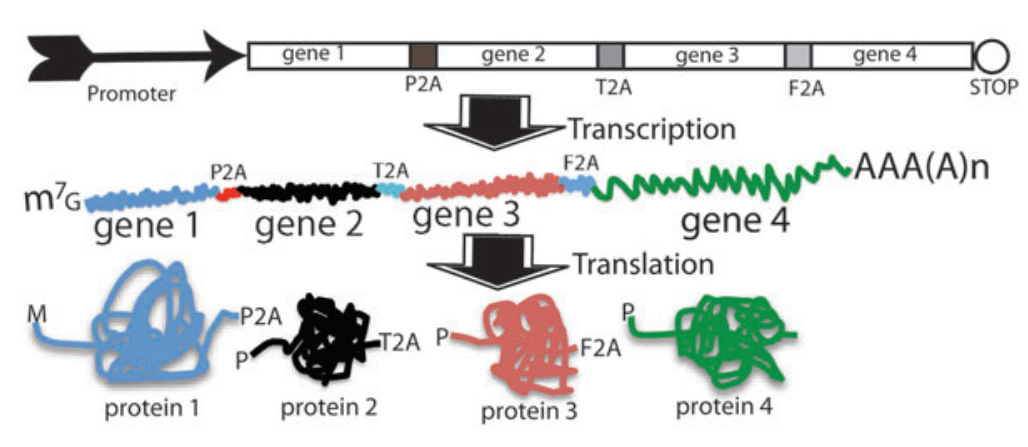

IRES

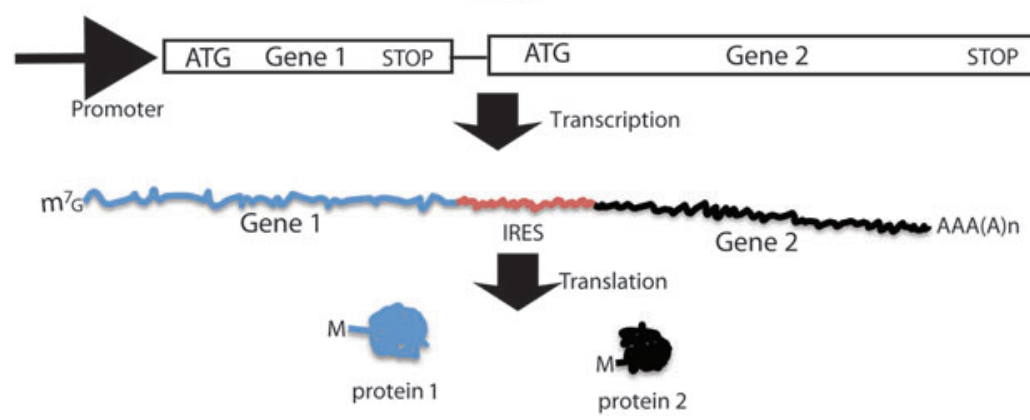

capacity. EBV plasmids replicate once per cell cycle in synchrony with the host chromosomes, and have a low mutation rate compared with BPV- or SV40-based plasmids. Partitioning of EBV plasmids does not seem to be random, but the retention mechanism of the EBV vector is imperfect, resulting in a slow loss of plasmids at around 5\% each cell cycle if the selection pressure is removed [93]. This feature was employed to generate footprint-free iPSCs [4-6]. Unlike other episomal circular DNA viruses, EBV has a large genome of $172 \mathrm{~kb}$, and therefore EBV vectors can accommodate a large DNA fragment. EBV-based vectors work mainly in primate cells, and are reported not to persist in rodent cells although one group reported that some rodent cell lines supported the long-term maintenance of EBV vectors [94].

\section{A Peptides and IRES for Construction of Polycistron Vectors}

IRES and $2 \mathrm{~A}$ peptides are two popular means for achieving the coexpression of multiple genes (Fig. 3) among other approaches, such as the utilization of multiple promoters and fusion proteins [95]. 2A is a short peptide (18-22 amino acids) that mediates the coexpression of two proteins from a single open reading frame (ORF) [95-97]. The upstream protein terminates at the $2 \mathrm{~A}$ terminal glycine in a fashion independent of the traditional stop codon, and the downstream protein initiates at a proline independent of the initiation codon. The 2A-peptide-mediated coexpression of transgenes has gained popularity recently due to its small size, efficiency, stoichiometry, and availability of various functional variants. Its small size is an invaluable feature in terms of constructing reprogramming vectors due to the need to assemble four genes into a single vector. The use of $2 \mathrm{~A}$ variants can avoid potential intramolecular homologous recombination of polycistrons, and allows for the expression of multiple genes (up to five genes). There are four widely used $2 \mathrm{~A}$ sequences, which are derived from the foot-and-mouth disease virus (F2A), porcine teschovirus-1 (P2A), Thoseaasigna virus (T2A), and equine rhinitis A virus (E2A), with $\mathrm{P} 2 \mathrm{~A}$ as the most effective one [98]. 2A is active in all eukaryotic cells [99], but not in prokaryotes [100]. 2A sequences (54-66 bp) are short compared to IRES and internal promoters, and therefore provide an advantage in vector design because of the limited packaging capacity of the widely used lentiviral vectors and RVs. The following two points should be kept in mind when 2A peptides are used for the construction of polycistronic vectors. First, there is still an imbalance of expression between proteins upstream and downstream of $2 \mathrm{~A}$, with the upstream protein being translated at a higher level, although this imbalance is not as severe as with IRES; second, the resulting $\mathrm{N}$-terminal protein retains a $2 \mathrm{~A}$ peptide and the spacer GSG if included during vector construction, while the $\mathrm{C}$-terminal protein retains an extra proline at its very $\mathrm{N}$ terminus.

IRES is a stretch of highly structured RNA of about $450 \mathrm{nts}$ that directs a cap-independent initiation of protein synthesis from a downstream coding RNA [101-104]. This property is employed to design dicistronic expression cassette under the control of a single promoter in which the first cistron is translated by a canonical cap-dependent initiation, but the second cistron is translated via IRES-mediated internal initiation of translation. In dicistronic vectors, the cistron downstream of IRES usually has a lower level of expression (6\%-100\% that of the upstream gene) [105]. Utilization of IRES and $2 \mathrm{~A}$ for coexpression requires different vector design consideration. The stop codon of the first gene in the $2 \mathrm{~A}$ vector should be removed and the two cistrons linked by $2 \mathrm{~A}$ should be in-frame to form a single ORF, while the stop codon of the first cistron should be retained in the IRES vectors and IRES connects two distinct ORFs. There are two limitations to IRES-mediated coexpression: (1) IRES is long, and this is a negative attribute when vector capacity is limited as in RVs; (2) the expression 


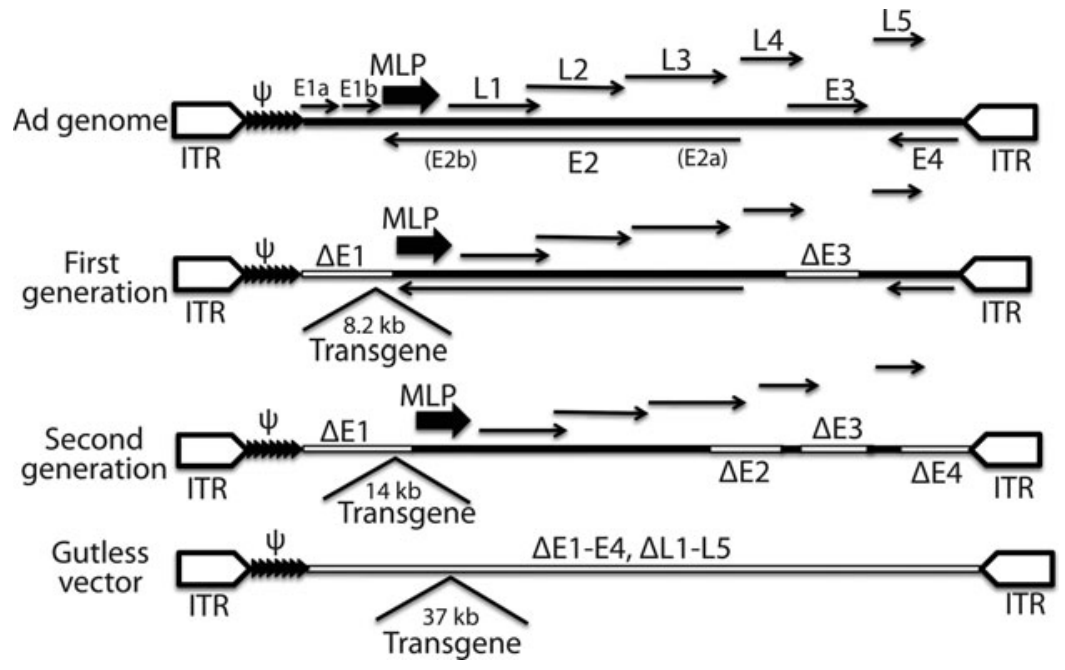

FIG. 4. Genome structure of the adenoviral vectors of the three generations along with that of the wild-type $A d$ genome. $\psi$, packaging signal (tandem filled triangles); $\Delta$ indicates deletion of genes; ITR, inverted terminal repeat; MLP, major late promoter (large arrows); thick lines represent viral sequences; open boxes denote deletion of viral sequences; thin arrows indicate viral genes and their direction of transcription; open pentagons are ITRs. Numbers are insertion capacity of transgenes. of the second gene is compromised. Thus, IRES is less popular in reprogramming constructs.

\section{PiggyBac Transposon and Vectors}

$\mathrm{PB}$ is a nonviral 2,472-bp DNA transposon isolated from the cabbage looper moth. PB transposes in a wide range of host genomes from yeast to human [106-108]. The PB transposon consists of $3^{\prime}$ and $5^{\prime}$ terminal repeat domains (TRDs) and an ORF encoding the PB transposase, the former of which delimit the transposon cassette for integration. Both the $3^{\prime}$ and $5^{\prime}$ TRDs contain a 13-bp terminal inverted repeat and a 19-bp internal inverted repeat. The $3^{\prime}$ TRD has a 31-bp spacer while the $5^{\prime}$ TRD spacer is only 3-bp long. In the $\mathrm{PB}$ vector system, the PB transposase can be provided in trans, and a transgene expression cassette is sandwiched between the two TRDs in place of the native PB transposase [109-111]. A typical PB gene delivery system therefore includes a helper plasmid to express the PB transposase, and a transposon donor plasmid in which the two cis-acting TRDs enclose a transgene expression cassette. PB transposition follows a cut-and-paste mechanism, and the transgene cassette is integrated into genomes at TTAA sites. The PB transposition process initiates with nicking at the transposon $3^{\prime}$ end, and includes hairpin formation between the transposon $5^{\prime}$-end-TTAA overhang and its $3^{\prime} \mathrm{OH}$, hairpin resolution, target joining, and target repair [110]. The PB transposase is solely responsible for catalyzing all of these processes. Unlike transpositions with other DDE family recombinases, PB transposition does not require DNA synthesis, and results in the precise excision of transposon from the host DNA due to the tetranucleotide cohesive overhang (TTAA) left behind on both the flanking host DNA and the transposon ends, which can undergo a footprint-free repair through a simple process of TTAA base pairing and ligation [110]. Although TRDs are sufficient for interplasmid transposition, efficient genome transposition requires internal sequences adjacent to both the $5^{\prime}$ and $3^{\prime}$ internal inverted repeats [112]. The integrated expression cassette together with the transposon terminal elements can be precisely excised by transient expression of the reintroduced PB transposase. This excision process leaves no footprint behind. PB vectors constitute a nonviral, genome-integrating gene de- livery system representing a cheaper and simpler approach than viral systems. They also have a much larger cargo capacity than retroviral systems. PB transposons have the highest transposition efficiency among DNA transposons, but still give a significantly lower rate of stable transposition (integration rate) compared to viral vectors [111]. These features allow the use of $\mathrm{PB}$ vectors to generate footprint-free iPSCs $[8,113]$.

\section{Adenoviral Vectors}

Adenoviral vectors are the second most widely used vectors in clinical trials after RVs owing to their high capacity for transgene insertion, high virus yield, efficient transduction into a wide range of cells, and higher safety profile than integrating vectors [114]. Adenovirus is a nonenveloped double-stranded DNA virus with an icosahedral capsid. The genome is a nonsegmented linear DNA with a viral terminal protein covalently attached to each $5^{\prime}$ terminus of both viral ends at the two inverted terminal repeats (ITRs). The genome encodes two groups of overlapping genes on both strands, the early (El to $E 4)$ and the
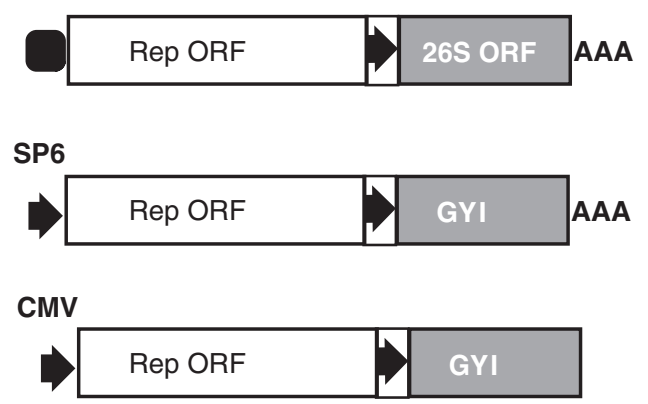

FIG. 5. Alphaviral vectors. Upper: structure of an alphaviral genome. Middle: alphaviral vector design for in vitro preparation of RNA replicon (noninfectious) using SP6 promoter. Lower: alphaviral plasmid design for in vivo generation of RNA replicons via a eukaryotic promoter. Open box, nonstructural ORF of the alphaviral genome; gray box, structural ORF of an alphaviral genome; arrow in a box, the alphaviral subgenomic promoter; arrows, SP6 or CMV promoters; filled rounded square, RNA cap. 


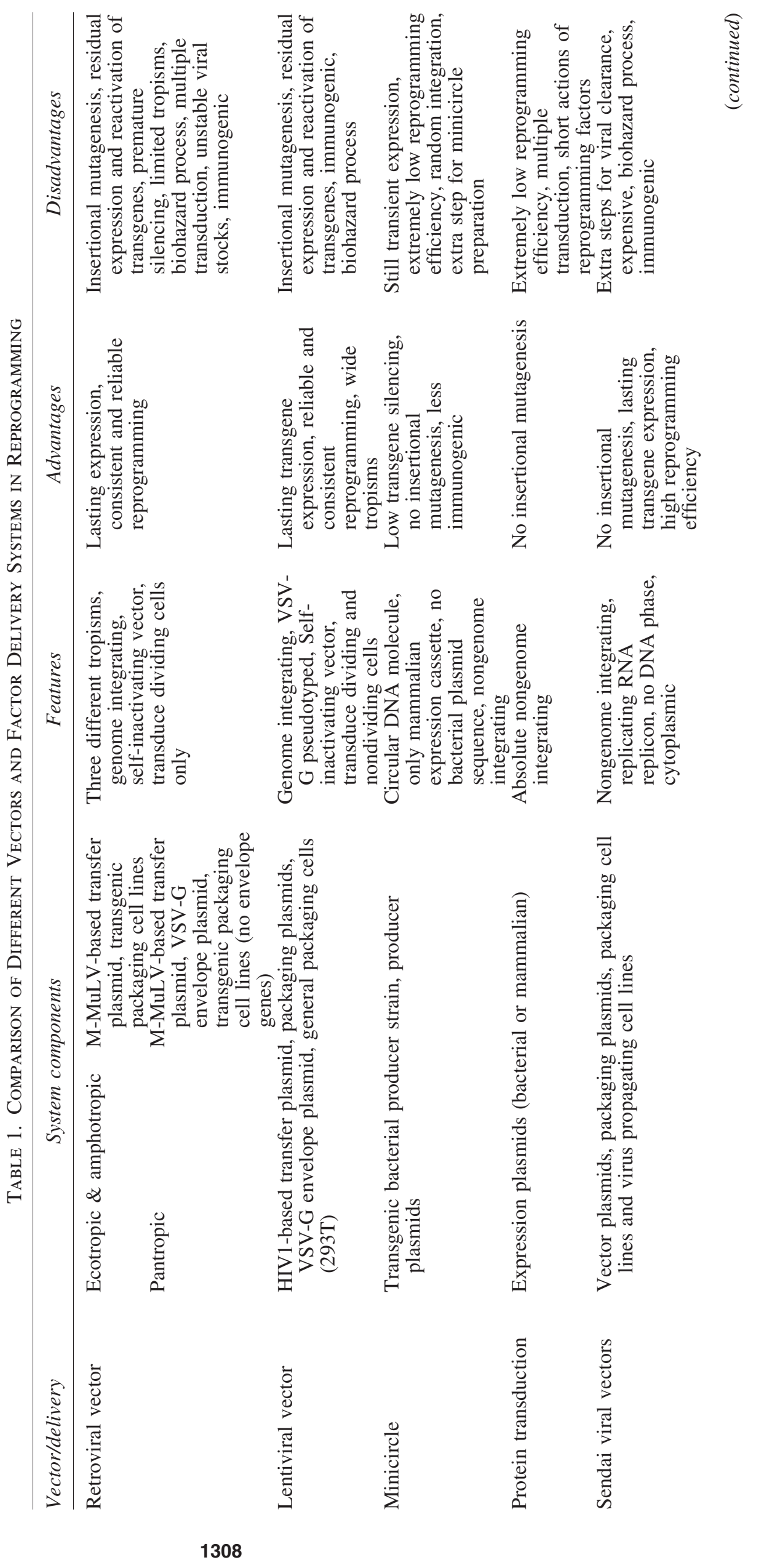




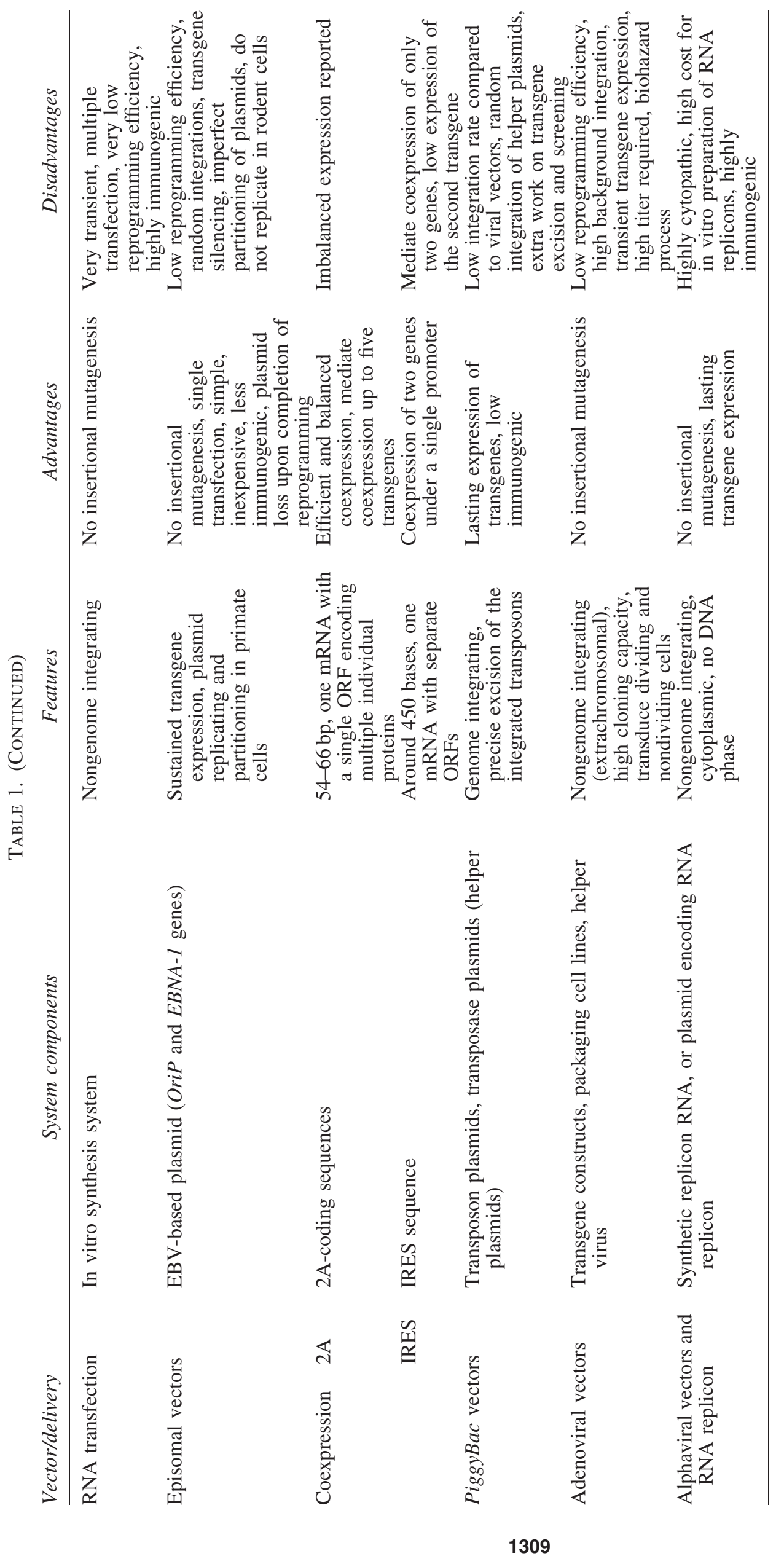


late genes ( $L 1$ to $L 5)$, which are expressed before and after replication of the viral genome, respectively $[114,115]$. Each gene gives rise to multiple protein products through alternative splicing. Adenoviral vectors are mostly based on the two well-characterized human adenoviruses: $A d 2$ and Ad5 [115-117]. The development of adenoviral vectors has roughly three generations [118]. The first generation of vectors has $E 1$ deleted to make virus replication incompetent, because E1 is responsible for the activation of both the early and the late viral genes, and thus for viral replication [117] (Fig. 4). The E1 function in the first-generation vector is provided in trans from a complementary packaging cell line, which is usually HEK293 transformed with the adenovirus E1 region. Some first-generation vectors are also devoid of the $E 3$ gene to make more room for transgene insertion. The first-generation vector can accommodate up to $8.2 \mathrm{~kb}$ of exogenous sequence. Two issues with the firstgeneration vectors are the presence of some replication competent adenoviruses (RCAs), and immune responses from the transduced cells and/or tissue/animals. The secondgeneration vectors have part or all of their $E 2$ and $E 4$ genes deleted in addition to the $E 1$ and $E 3$ deletions (Fig. 4). These additional deletions have threefold benefits: reduced RCAs, reduced immune response, and additional room (up to $14 \mathrm{~kb}$ ) for transgene insertion. The last generation of adenoviral vectors (also known as gutless vectors, gutted vectors, or helper-dependent $A d$ vectors) is devoid of all viral genes, leaving just the two ITRs and the packaging signal, so as to reduce vector toxicity and immunogenicity, and to make more room for transgene insertion [118] (Fig. 4). With most of the 36-kb sequence of the genome deleted, the gutless vector can accommodate up to $37 \mathrm{~kb}$ of foreign sequences without compromising viral growth and titer. A helper virus is needed for the gutless vector because it is not possible to establish a complementary cell line due to toxicity of some viral proteins and the need for a high level of viral proteins for viral packaging. Like lentiviral vectors, adenoviral vectors transduce both dividing and nondividing cells. Relevant to reprogramming is that adenoviral vectors are largely episomal because adenovirus exists as an extrachromosomal entity. A shortcoming associated with this feature is the shortterm expression of transgenes compared with the integrating LVs and RVs. This transient nature of transgene expression makes the efficiency of adenoviral reprogramming extremely low [7]. Adenoviral vectors also have a high level of background integration [119], and this constitutes a concern when these vectors are employed to generate footprint-free iPSCs for clinical application. Adenoviral constructs can be difficult to clone due to their large size [117].

\section{Alphaviral Vectors and RNA Replicon}

Alphavirus is an enveloped, single-stranded, positivesense, capped, and polyadenylated RNA virus with a genome of about 11,700 nucleotides [120]. Well-known alphaviruses for vector design include the Sindbis virus (SIN), Semliki forest virus (SFV), and Venezuelan equine encephalitis virus (VEE). The alphaviral genomes include two ORFs (nonstructural ORF and structural ORF), both of which encode polyproteins (Fig. 5). The $5^{\prime}$ nonstructural ORF encodes a polyprotein that generally gives rise to four nonstructural proteins (or replicase proteins, $\mathrm{nsP} 1$ to $\mathrm{nsP} 4$ ) and some cleavage intermediates. These proteins function mainly as an RNA-dependent RNA polymerase, and therefore this ORF is considered an RNA replicase/transcriptase gene (Rep). The structural ORF (26S ORF) encodes structural proteins: three main structural proteins [C (capsid), E1, and E2] and two minor structural proteins (E3 and 6K). E2 and E3 are products of a precursor protein, PE2. Genomic RNA serves as the direct template for translation of the nonstructural proteins, and as the template for synthesis of the negative-strand RNAs: (-)RNA. (-)RNA is an exact complement of the genomic RNA except for the presence of an unpaired $G$ at its $3^{\prime}$ end. (-)RNA serves as the template for synthesis of new genomic RNAs, and also as the template for transcription of the $26 S$ mRNA under the direction of the subgenomic $26 S$ promoter. The $26 S$ mRNA is capped and polyadenylated, and serves as the template for translation of the structural proteins. Structural proteins are not required for synthesis of the $(-)$ RNA, replication of the $(+)$ RNA, and the cytoplasmic transcription of the $26 \mathrm{~S}$ mRNA. Therefore, an RNA genome deleted of the structural ORF can replicate in cells (RNA replicon), but is not infectious. Alphaviral vectors can be infectious and noninfectious. Infectious vector is made by insertion of transgenes into the complete genome before or after the structural ORF with the inclusion of an additional subgenomic promoter [121]. A noninfectious vector is made possible by replacing the structural ORF with transgene-coding sequences [122]. Noninfectious vectors can be packaged into virions when the structural proteins are provided in trans. Noninfectious RNA replicons can be delivered directly into cells as RNAs synthesized in vitro using SP6 or T7 promoters (Fig. 5). Such synthetic, noninfectious RNA replicons encoding the reprogramming factors were recently used to generate footprint-free iPSCs [16]. DNA-based alphaviral vectors are reported [123-125]. In this case, RNA replicons are transcribed from conventional plasmids in the nuclei of the transfected cells using a eukaryotic promoter, such as the CMV or RSV promoters (Fig. 5). The RNA replicons are then exported from the nucleus into the cytoplasm, where they can undergo translation of replicase, (-)RNA synthesis, and transgene transcription and translation. Alphaviral vectors pose no risk of integration into the host genome, a desired feature for the generation of footprint-free iPSC lines. However, alphaviral vectors are highly cytopathic, and host cells die in a few days postinfection. Point mutations in the $5^{\prime}$ UTR and in the nsP2 protein can alleviate the cytopathic effect of alphaviral vectors by slowing down the replication of RNA replicons [126,127].

\section{Concluding Remarks}

Factor reprogramming requires sustained expression of the four reprogramming factors for $\sim 10-30$ days. After reprogramming, transgene expression and retention are detrimental or pose potential risks [128]. Lentiviral and simple RVs provide sustained expression of transgenes, and transgenes are silenced in the reprogrammed pluripotent cells. However, the silencing process can occur at undesirable points in time, either too early or too late. In addition, RVs integrate into the reprogrammed genomes, posing risks of insertional mutagenesis, and residual expression and reactivation of the transgenes. Many nonintegrating approaches (protein transduction, 
RNA transfection, transient transfection, minicircle, and episomal plasmids) generally cannot support sustained expression of transgenes and suffer from low efficiencies of reprogramming. Alphaviral vectors are theoretically ideal reprogramming vehicles, but their strong cytopathic effects compromise their values. Sendai viral vectors might meet the complex requirements for factor reprogramming owing to their nonintegrating nature, self-replicating property, controllable removal of viral replicons, relatively low toxicity, and the ability to accommodate multiple exogenous genes. Despite their relatively low reprogramming efficiency, EBV-based episomal plasmids are currently a feasible vehicle choice due to their simplicity, self-replicating nature, nonintegrating property, low immunogenicity, and low toxicity. There might be some stones left unturned, and a more efficient, safer, and nonintegrating reprogramming approach could be developed in the future using some novel transgene vectors or factor delivery systems.

\section{Glossary}

Transduction: a gene transfer process in which replication-incompetent viral particles "infect" cells or tissues in vivo or in vitro. This term distinguishes itself from a normal viral infection by any replication-competent virus in which viruses invade cells and/or tissues, and subsequently replicate inside the host cells and spread to neighboring cells or tissues. Transduction also refers to the process of protein delivery into cells.

Packaging signal: a region in a viral chromosome that is essential for the efficient packaging of viral genomes.

\section{Acknowledgments}

The author's research is supported by UAB new faculty development fund. The author thanks Dr. Kevin Pawlik for his critical reading. He also appreciates the critical reviews by the two anonymous reviewers. Their inputs made Table 1 and other improvements in this contribution possible.

\section{Author Disclosure Statement}

The author declares no competing financial interests.

\section{References}

1. Takahashi K and S Yamanaka. (2006). Induction of pluripotent stem cells from mouse embryonic and adult fibroblast cultures by defined factors. Cell 126: 663-676.

2. Yu J, MA Vodyanik, K Smuga-Otto, J AntosiewiczBourget, JL Frane, S Tian, J Nie, GA Jonsdottir, V Ruotti, et al. (2007). Induced pluripotent stem cell lines derived from human somatic cells. Science 318:1917-1920.

3. Hu K and I Slukvin. (2012). Induction of pluripotent stem cells from umbilical cord blood. In: Encyclopedia of Molecular Cell Biology and Molecular Medicine: Stem Cells. RA Meyers, ed. Wiley-VCH Verlag GmbH \& Co. KGaA., pp 1-25. DOI: 10.1002/3527600906.mcb.2012 00006.

4. Yu J, K Hu, K Smuga-Otto, S Tian, R Stewart, II Slukvin and JA Thomson. (2009). Human induced pluripotent stem cells free of vector and transgene sequences. Science 324:797-801.
5. Hu K, J Yu, K Suknuntha, S Tian, K Montgomery, KD Choi, R Stewart, JA Thomson and II Slukvin. (2011). Efficient generation of transgene-free induced pluripotent stem cells from normal and neoplastic bone marrow and cord blood mononuclear cells. Blood 117:e109-e119.

6. Hu K and I Slukvin. (2013). Generation of transgenefree iPSC lines from human normal and neoplastic blood cells using episomal vectors. Methods Mol Biol 997: 163-176.

7. Stadtfeld M, M Nagaya, J Utikal, G Weir and K Hochedlinger. (2008). Induced pluripotent stem cells generated without viral integration. Science 322:945-949.

8. Woltjen K, IP Michael, P Mohseni, R Desai, M Mileikovsky, R Hamalainen, R Cowling, W Wang, P Liu, et al. (2009). piggyBac transposition reprograms fibroblasts to induced pluripotent stem cells. Nature 458: 766-770.

9. Kaji K, K Norrby, A Paca, M Mileikovsky, P Mohseni and K Woltjen. (2009). Virus-free induction of pluripotency and subsequent excision of reprogramming factors. Nature 458:771-775.

10. Chang CW, YS Lai, KM Pawlik, K Liu, CW Sun, C Li, TR Schoeb and TM Townes. (2009). Polycistronic lentiviral vector for "Hit and Run" reprogramming of adult skin fibroblasts to induced pluripotent stem cells. Stem Cells 27:1042-1049.

11. Okita K, M Nakagawa, HJ Hong, T Ichisaka and S Yamanaka. (2008). Generation of mouse induced pluripotent stem cells without viral vectors. Science 322:949-953.

12. Jia F, KD Wilson, N Sun, DM Gupta, M Huang, Z Li, NJ Panetta, ZY Chen, RC Robbins, et al. (2010). A nonviral minicircle vector for deriving human iPS cells. Nat Methods 7:197-199.

13. Zhou HY, SL Wu, JY Joo, SY Zhu, DW Han, TX Lin, S Trauger, G Bien, S Yao, et al. (2009). Generation of induced pluripotent stem cells using recombinant proteins. Cell Stem Cell 4:381-384.

14. Warren L, PD Manos, T Ahfeldt, YH Loh, H Li, F Lau, W Ebina, PK Mandal, ZD Smith, et al. (2010). Highly efficient reprogramming to pluripotency and directed differentiation of human cells with synthetic modified mRNA. Cell Stem Cell 7:618-630.

15. Seki T, S Yuasa, M Oda, T Egashira, K Yae, D Kusumoto, H Nakata, S Tohyama, H Hashimoto, et al. (2010). Generation of induced pluripotent stem cells from human terminally differentiated circulating $\mathrm{T}$ cells. Cell Stem Cell 7:11-14.

16. Yoshioka N, E Gros, HR Li, S Kumar, DC Deacon, C Maron, AR Muotri, NC Chi, XD Fu, BD Yu and SF Dowdy. (2013). Efficient generation of human iPSCs by a synthetic self-replicative RNA. Cell Stem Cell 13:246254.

17. Hu K. (2014). All roads lead to the induced pluripotent stem cells: the technologies of iPSC generation. Stem Cells Dev [Epub ahead of print]; DOI: 10.1089/scd .2013.0620.

18. Walther W and U Stein. (2000). Viral vectors for gene transfer: a review of their use in the treatment of human diseases. Drugs 60:249-271.

19. Cepko C and W Pear. (1996). Overview of the retrovirus transduction system. In: Current Protocols in Molecular Biology. FM Ausubel, R Brent, RE Kingston, DD Moore, JG Seidman, JA Smith, K Struhl, eds. John Wiley \& Sons, Inc., USA, pp 9.9.1-9.9.16. 
20. Takahashi K, K Tanabe, M Ohnuki, M Narita, T Ichisaka, K Tomoda and S Yamanaka. (2007). Induction of pluripotent stem cells from adult human fibroblasts by defined factors. Cell 131:861-872.

21. Goff SP. (2007). Retroviridea: The Retroviruses and Their Replication. In: Fields' Virology. DM Knipe, PM Howley, eds. Tolters Kluwer Health/Lippincott Williams \& Wilkins, Philadelphia, PA, pp 1999-2069.

22. Rein A. (2011). Murine leukemia viruses: objects and organisms. Adv Virol 2011:403419.

23. Miller AD. (1996). Cell-surface receptors for retroviruses and implications for gene transfer. Proc Natl Acad Sci U S A 93:11407-11413.

24. Weiss RA and CS Tailor. (1995). Retrovirus receptors. Cell 82:531-533.

25. Friedmann T and JK Yee. (1995). Pseudotyped retroviral vectors for studies of human gene-therapy. Nat Med $1: 275-277$.

26. Finkelshtein D, A Werman, D Novick, S Barak and M Rubinstein. (2013). LDL receptor and its family members serve as the cellular receptors for vesicular stomatitis virus. Proc Natl Acad Sci U S A 110:7306-7311.

27. Morita S, T Kojima and T Kitamura. (2000). Plat-E: an efficient and stable system for transient packaging of retroviruses. Gene Ther 7:1063-1066.

28. Pear W. (1996). Transient transfection methods for preparation of high-titer retroviral supernatants. In: Current Protocols in Molecular Biology. FM Ausubel, R Brent, RE Kingston, DD Moore, JG Seidman, JA Smith, K Struhl, eds. John Wiley \& Sons, Inc., USA, pp 9.11.11-19.11.18.

29. Miller DG, MA Adam and AD Miller. (1990). Genetransfer by retrovirus vectors occurs only in cells that are actively replicating at the time of infection. Mol Cell Biol 10:4239-4242.

30. Roe TY, TC Reynolds, G Yu and PO Brown. (1993). Integration of murine leukemia-virus DNA depends on mitosis. Embo J 12:2099-2108.

31. Wolf D and SP Goff. (2007). TRIM28 mediates primer binding site-targeted silencing of murine leukemia virus in embryonic cells. Cell 131:46-57.

32. Wolf D and SP Goff. (2009). Embryonic stem cells use ZFP809 to silence retroviral DNAs. Nature 458:12011204.

33. Antoniou MN, KA Skipper and O Anakok. (2013). Optimizing retroviral gene expression for effective therapies. Hum Gene Ther 24:363-374.

34. Hotta A and J Ellis. (2008). Retroviral vector silencing during iPS cell induction: an epigenetic beacon that signals distinct pluripotent states. J Cell Biochem 105:940 948.

35. Srinivasakumar N, M Zaboikin, AM Tidball, AA Aboud, MD Neely, KC Ess, AB Bowman and FG Schuening. (2013). Gammaretroviral vector encoding a fluorescent marker to facilitate detection of reprogrammed human fibroblasts during iPSC generation. Peer J 1:e224.

36. Federico M. (2003). From lentiviruses to lentivirus vectors. Methods Mol Biol 229:3-15.

37. Marino MP, MJ Luce and J Reiser. (2003). Small- to large-scale production of lentivirus vectors. Methods Mol Biol 229:43-55.

38. Lotti F and F Mavilio. (2003). The choice of a suitable lentivirus vector: transcriptional targeting. Methods Mol Biol 229:17-27.
39. Follenzi A and L Naldini. (2002). Generation of HIV-1 derived lentiviral vectors. Method Enzymol 346:454465.

40. Freed EO and MA Martin. (2007). HIVs and their replication. In: Fields' Virology. DM Knipe, PM Howley, eds. Lippincott Williams \& Wilkins, Philadelphia, pp 2107-2185.

41. Schambach A, D Zychlinski, B Ehrnstroem and C Baum. (2013). Biosafety features of lentiviral vectors. Hum Gene Ther 24:132-142.

42. Kutner RH, XY Zhang and J Reiser. (2009). Production, concentration and titration of pseudotyped HIV-1-based lentiviral vectors. Nat Protoc 4:495-505.

43. Pacchia AL, S Mukherjee and JP Dougherty. (2003). Choice and use of appropriate packaging cell types. Methods Mol Biol 229:29-42.

44. Broussau S, N Jabbour, G Lachapelle, Y Durocher, R Tom, J Transfiguracion, R Gilbert and B Massie. (2008). Inducible packaging cells for large-scale production of lentiviral vectors in serum-free suspension culture. Mol Ther 16:500-507.

45. Fassati A. (2006). HIV infection of non-dividing cells: a divisive problem. Retrovirology 3:74.

46. Li LH and H Clevers. (2010). Coexistence of quiescent and active adult stem cells in mammals. Science 327:542545.

47. Chen ZY, CY He, L Meuse and MA Kay. (2004). Silencing of episomal transgene expression by plasmid bacterial DNA elements in vivo. Gene Ther 11:856-864.

48. Chen ZY, CY He, A Ehrhardt and MA Kay. (2003). Minicircle DNA vectors devoid of bacterial DNA result in persistent and high-level transgene expression in vivo. Mol Ther 8:495-500.

49. Kay MA, CY He and ZY Chen. (2010). A robust system for production of minicircle DNA vectors. Nat Biotechnol 28:1287-1289.

50. Bigger BW, O Tolmachov, JM Collombet, M Fragkos, I Palaszewski and C Coutelle. (2001). An araC-controlled bacterial cre expression system to produce DNA minicircle vectors for nuclear and mitochondrial gene therapy. J Biol Chem 276:23018-23027.

51. Nehlsen K, S Broll and J Bode. (2006). Replicating minicircles: generation of nonviral episomes for the efficient modification of dividing cells-Research article. Gene Ther Mol Biol 10B:233-243.

52. Mayrhofer P, M Blaesen, M Schleef and W Jechlinger. (2008). Minicircle-DNA production by site specific recombination and protein-DNA interaction chromatography. J Gene Med 10:1253-1269.

53. Matsushita M and H Matsui. (2005). Protein transduction technology. J Mol Med (Berl) 83:324-328.

54. Noguchi H, M Matsushita, N Kobayashi, MF Levy and S Matsumoto. (2010). Recent advances in protein transduction technology. Cell Transplant 19:649-654.

55. Noguchi H and S Matsumoto. (2006). Protein transduction technology: a novel therapeutic perspective. Acta Med Okayama 60:1-11.

56. El-Sayed A, S Futaki and H Harashima. (2009). Delivery of macromolecules using arginine-rich cell-penetrating peptides: ways to overcome endosomal entrapment. Aaps J 11:13-22.

57. Wadia JS and SF Dowdy. (2002). Protein transduction technology. Curr Opin Biotechnol 13:52-56.

58. Kim D, CH Kim, JI Moon, YG Chung, MY Chang, BS Han, S Ko, E Yang, KY Cha, R Lanza and KS Kim. 
(2009). Generation of human induced pluripotent stem cells by direct delivery of reprogramming proteins. Cell Stem Cell 4:472-476.

59. Frankel AD and CO Pabo. (1988). Cellular uptake of the tat protein from human immunodeficiency virus. Cell 55:1189-1193.

60. Dowdy SF. (2005). Protein transduction: generation of fulllength transducible proteins using the TAT system. In: Current Protocols in Cell Biology. JS Bonifacino, M Dasso, JB Harford, J Lippincott-Schwartz, KM Yamada, eds. John Wiley \& Sons, Inc., Bethesda, MD, pp 20.22.2120.22.25.

61. Vives E, P Brodin and B Lebleu. (1997). A truncated HIV-1 Tat protein basic domain rapidly translocates through the plasma membrane and accumulates in the cell nucleus. J Biol Chem 272:16010-16017.

62. Elliott G and P O'Hare. (1997). Intercellular trafficking and protein delivery by a herpesvirus structural protein. Cell 88:223-233.

63. Derossi D, AH Joliot, G Chassaing and A Prochiantz. (1994). The third helix of the Antennapedia homeodomain translocates through biological membranes. J Biol Chem 269:10444-10450.

64. Pietersz GA, W Li and V Apostolopoulos. (2001). A 16mer peptide (RQIKIWFQNRRMKWKK) from antennapedia preferentially targets the Class I pathway. Vaccine 19:1397-1405.

65. Richard JP, K Melikov, E Vives, C Ramos, B Verbeure, MJ Gait, LV Chernomordik and B Lebleu. (2003). Cellpenetrating peptides-A reevaluation of the mechanism of cellular uptake. J Biol Chem 278:585-590.

66. Heitz F, MC Morris and G Divita. (2009). Twenty years of cell-penetrating peptides: from molecular mechanisms to therapeutics. Br J Pharmacol 157:195-206.

67. Schwarze SR, A Ho, A Vocero-Akbani and SF Dowdy. (1999). In vivo protein transduction: Delivery of a biologically active protein into the mouse. Science 285:1569 1572.

68. Futaki S, T Suzuki, W Ohashi, T Yagami, S Tanaka, K Ueda and Y Sugiura. (2001). Arginine-rich peptides-An abundant source of membrane-permeable peptides having potential as carriers for intracellular protein delivery. J Biol Chem 276:5836-5840.

69. Walev I, SC Bhakdi, F Hofmann, N Djonder, A Valeva, K Aktories and S Bhakdi. (2001). Delivery of proteins into living cells by reversible membrane permeabilization with streptolysin-O. Proc Natl Acad Sci U S A 98: 3185-3190.

70. Agarwal S. (2006). Cellular reprogramming. Method Enzymol 420:265-283.

71. Cho HJ, CS Lee, YW Kwon, JS Paek, SH Lee, J Hur, EJ Lee, TY Roh, IS Chu, et al. (2010). Induction of pluripotent stem cells from adult somatic cells by protein-based reprogramming without genetic manipulation. Blood 116:386-395.

72. Lamb RA and GD Parks. (2007). Paramyxoviridae: The viruses and their replcation. In: Fields Virology. DM Knipe, PM Howley, eds. Lippincott Williams \& Wilkins, Philadelphia, PA, pp 1449-1496.

73. Bitzer M, S Armeanu, UM Lauer and WJ Neubert. (2003). Sendai virus vectors as an emerging negativestrand RNA viral vector system. J Gene Med 5:543-553.

74. Hasan MK, A Kato, T Shioda, Y Sakai, DS Yu and Y Nagai. (1997). Creation of an infectious recombinant
Sendai virus expressing the firefly luciferase gene from the 3' proximal first locus. J Gen Virol 78:2813-2820.

75. Yoshizaki M, T Hironaka, H Iwasaki, H Ban, Y Tokusumi, A Iida, Y Nagai, M Hasegawa and M Inoue. (2006). Naked Sendai virus vector tacking all of the enveloperelated genes: reduced cytopathogenicity and immunogenicity. J Gene Med 8:1151-1159.

76. Nishimura K, M Sano, M Ohtaka, B Furuta, Y Umemura, Y Nakajima, Y Ikehara, T Kobayashi, H Segawa, et al. (2011). Development of defective and persistent Sendai virus vector: a unique gene delivery/expression system ideal for cell reprogramming. J Biol Chem 286:47604771.

77. Li HO, YF Zhu, M Asakawa, H Kuma, T Hirata, Y Ueda, YS Lee, M Fukumura, A Iida, et al. (2000). A cytoplasmic RNA vector derived from nontransmissible Sendai virus with efficient gene transfer and expression. J Virol 74:6564-6569.

78. Inoue M, Y Tokusumi, H Ban, T Kanaya, T Tokusumi, Y Nagai, A Iida and M Hasegawa. (2003). Nontransmissible virus-like particle formation by F-deficient sendai virus is temperature sensitive and reduced by mutations in $\mathrm{M}$ and HN proteins. J Virol 77:3238-3246.

79. Ban H, N Nishishita, N Fusaki, T Tabata, K Saeki, M Shikamura, N Takada, M Inoue, M Hasegawa, S Kawamata and S Nishikawa. (2011). Efficient generation of transgene-free human induced pluripotent stem cells (iPSCs) by temperature-sensitive Sendai virus vectors. Proc Natl Acad Sci U S A 108:14234-14239.

80. Fusaki N, H Ban, A Nishiyama, K Saeki and M Hasegawa. (2009). Efficient induction of transgene-free human pluripotent stem cells using a vector based on Sendai virus, an RNA virus that does not integrate into the host genome. Proc Jpn Acad Ser B Phys Biol Sci 85:348-362.

81. Malone RW, PL Felgner and IM Verma. (1989). Cationic liposome-mediated RNA transfection. Proc Natl Acad Sci U S A 86:6077-6081.

82. Bringmann A, SA Held, A Heine and P Brossart. (2010). RNA vaccines in cancer treatment. J Biomed Biotechnol 2010:623687.

83. Nguyen J and FC Szoka. (2012). Nucleic acid delivery: the missing pieces of the puzzle? Acc Chem Res 45:11531162.

84. Weide B, C Garbe, HG Rammensee and S Pascolo. (2008). Plasmid DNA- and messenger RNA-based anticancer vaccination. Immunol Lett 115:33-42.

85. Gallie DR. (1991). The cap and poly(A) tail function synergistically to regulate mRNA translational efficiency. Genes Dev 5:2108-2116.

86. Sclimenti CR and MP Calos. (1998). Epstein-Barr virus vectors for gene expression and transfer. Curr Opin Biotechnol 9:476-479.

87. Van Craenenbroeck K, P Vanhoenacker and G Haegeman. (2000). Episomal vectors for gene expression in mammalian cells. Eur J Biochem 267:5665-5678.

88. Lindner SE and B Sugden. (2007). The plasmid replicon of Epstein-Barr virus: mechanistic insights into efficient, licensed, extrachromosomal replication in human cells. Plasmid 58:1-12.

89. Yates JL, N Warren and B Sugden. (1985). Stable replication of plasmids derived from Epstein-Barr virus in various mammalian cells. Nature 313:812-815.

90. Yates J, N Warren, D Reisman and B Sugden. (1984). A cis-acting element from the Epstein-Barr viral genome 
that permits stable replication of recombinant plasmids in latently infected cells. Proc Natl Acad Sci U S A 81:38063810.

91. Reisman D, J Yates and B Sugden. (1985). A putative origin of replication of plasmids derived from EpsteinBarr virus is composed of two cis-acting components. Mol Cell Biol 5:1822-1832.

92. Yates JL, SM Camiolo and JM Bashaw. (2000). The minimal replicator of Epstein-Barr virus oriP. J Virol 74:4512-4522.

93. Kirchmaier AL and B Sugden. (1995). Plasmid maintenance of derivatives of oriP of Epstein-Barr virus. J Virol 69:1280-1283.

94. Mizuguchi H, T Hosono and T Hayakawa. (2000). Longterm replication of Epstein-Barr virus-derived episomal vectors in the rodent cells. FEBS Lett 472:173-178.

95. de Felipe P. (2004). Skipping the co-expression problem: the new 2A "CHYSEL" technology. Genet Vaccines Ther 2:13.

96. de Felipe P, GA Luke, LE Hughes, D Gani, C Halpin and MD Ryan. (2006). E unum pluribus: multiple proteins from a self-processing polyprotein. Trends Biotechnol 24:68-75.

97. Szymczak-Workman AL, KM Vignali and DA Vignali. (2012). Design and construction of 2A peptide-linked multicistronic vectors. Cold Spring Harb Protoc 2012:199-204.

98. Kim JH, SR Lee, LH Li, HJ Park, JH Park, KY Lee, MK Kim, BA Shin and SY Choi. (2011). High cleavage efficiency of a $2 \mathrm{~A}$ peptide derived from porcine teschovirus-1 in human cell lines, zebrafish and mice. PLoS One 6:e18556.

99. Donnelly MLL, LE Hughes, G Luke, H Mendoza, E ten Dam, D Gani and MD Ryan. (2001). The 'cleavage' activities of foot-and-mouth disease virus $2 \mathrm{~A}$ site-directed mutants and naturally occurring '2A-like' sequences. J Gen Virol 82:1027-1041.

100. de Felipe P, GA Luke, JD Brown and MD Ryan. (2010). Inhibition of 2A-mediated 'cleavage' of certain artificial polyproteins bearing $\mathrm{N}$-terminal signal sequences. Biotechnol J 5:213-223.

101. Belsham GJ. (2009). Divergent picornavirus IRES elements. Virus Res 139:183-192.

102. Jackson RJ and A Kaminski. (1995). Internal initiation of translation in eukaryotes: The picornavirus paradigm and beyond. RNA 1:985-1000.

103. Houdebine LM and J Attal. (1999). Internal ribosome entry sites (IRESs): reality and use. Transgenic Res 8:157-177

104. Pelletier J and N Sonenberg. (1988). Internal initiation of translation of eukaryotic mRNA directed by a sequence derived from poliovirus RNA. Nature 334:320-325.

105. Mizuguchi H, ZL Xu, A Ishii-Watabe, E Uchida and T Hayakawa. (2000). IRES-dependent second gene expression is significantly lower than cap-dependent first gene expression in a bicistronic vector. Mol Ther 1:376382.

106. Ding $\mathrm{S}, \mathrm{X} \mathrm{Wu}, \mathrm{G} \mathrm{Li}, \mathrm{M}$ Han, $\mathrm{Y}$ Zhuang and $\mathrm{T} \mathrm{Xu}$. (2005). Efficient transposition of the piggyBac (PB) transposon in mammalian cells and mice. Cell 122:473483.

107. Mitra R, J Fain-Thornton and NL Craig. (2008). piggyBac can bypass DNA synthesis during cut and paste transposition. Embo J 27:1097-1109.
108. Wu SCY, YJJ Meir, CJ Coates, AM Handler, P Pelczar, S Moisyadi and JM Kaminski. (2006). piggyBac is a flexible and highly active transposon as compared to Sleeping Beauty, Tol2 and Mos1 in mammalian cells. Proc Natl Acad Sci U S A 103:15008-15013.

109. Handler AM. (2002). Use of the piggyBac transposon for germ-line transformation of insects. Insect Biochem Molec 32:1211-1220.

110. Feschotte C. (2006). The piggyBac transposon holds promise for human gene therapy. Proc Natl Acad Sci U S A 103:14981-14982.

111. Kim A and I Pyykko. (2011). Size matters: versatile use of PiggyBac transposons as a genetic manipulation tool. Mol Cell Biochem 354:301-309.

112. Li X, RA Harrell, AM Handler, T Beam, K Hennessy and MJ Fraser, Jr. (2005). piggyBac internal sequences are necessary for efficient transformation of target genomes. Insect Mol Biol 14:17-30.

113. Yusa K, R Rad, J Takeda and A Bradley. (2009). Generation of transgene-free induced pluripotent mouse stem cells by the piggyBac transposon. Nat Methods 6:363369.

114. McConnell MJ and MJ Imperiale. (2004). Biology of adenovirus and its use as a vector for gene therapy. Hum Gene Ther 15:1022-1033.

115. Russell WC. (2000). Update on adenovirus and its vectors. J Gen Virol 81:2573-2604.

116. Zhang WW. (1999). Development and application of adenoviral vectors for gene therapy of cancer. Cancer Gene Ther 6:113-138.

117. Danthinne $X$ and MJ Imperiale. (2000). Production of first generation adenovirus vectors: a review. Gene Ther 7:1707-1714.

118. Alba R, A Bosch and M Chillon. (2005). Gutless adenovirus: last-generation adenovirus for gene therapy. Gene Ther 12 Suppl 1:S18-S27.

119. Harui A, S Suzuki, S Kochanek and K Mitani. (1999). Frequency and stability of chromosomal integration of adenovirus vectors. J Virol 73:6141-6146.

120. Strauss JH and EG Strauss. (1994). The alphaviruses: gene expression, replication, and evolution. Microbiol Rev 58:491-562.

121. Hahn CS, YS Hahn, TJ Braciale and CM Rice. (1992). Infectious Sindbis virus transient expression vectors for studying antigen processing and presentation. Proc Natl Acad Sci U S A 89:2679-2683.

122. Xiong C, R Levis, $P$ Shen, S Schlesinger, CM Rice and HV Huang. (1989). Sindbis virus: an efficient, broad host range vector for gene expression in animal cells. Science 243:1188-1191.

123. Herweijer H, JS Latendresse, $\mathrm{P}$ Williams, GF Zhang, I Danko, S Schlesinger and JA Wolff. (1995). A plasmidbased self-amplifying sindbis-virus vector. Hum Gene Ther 6:1161-1167.

124. Dubensky TW, DA Driver, JM Polo, BA Belli, EM Latham, CE Ibanez, S Chada, D Brumm, TA Banks, et al. (1996). Sindbis virus DNA-based expression vectors: Utility for in vitro and in vivo gene transfer. J Virol 70:508-519.

125. DiCiommo DP and R Bremner. (1998). Rapid, high level protein production using DNA-based semliki forest virus vectors. J Biol Chem 273:18060-18066.

126. Petrakova O, E Volkova, R Gorchakov, S Paessler, RM Kinney and I Frolov. (2005). Noncytopathic replication of 
Venezuelan equine encephalitis virus and eastern equine encephalitis virus replicons in mammalian cells. J Virol 79:7597-7608

127. Agapov EV, I Frolov, BD Lindenbach, BM Pragai, S Schlesinger and CM Rice. (1998). Noncytopathic Sindbis virus RNA vectors for heterologous gene expression. Proc Natl Acad Sci U S A 95:1298912994.

128. Golipour A, L David, Y Liu, G Jayakumaran, CL Hirsch, D Trcka and JL Wrana. (2012). A late transition in somatic cell reprogramming requires regulators distinct from the pluripotency network. Cell Stem Cell 11: 769-782.
Address correspondence to: Dr. Kejin $\mathrm{Hu}$

Department of Biochemistry and Molecular Genetics $U A B$ Stem Cell Institute

School of Medicine

University of Alabama at Birmingham Birmingham, AL 35294

E-mail: kejinhu@uab.edu

Received for publication December 16, 2013 Accepted after revision March 13, 2014 Prepublished on Liebert Instant Online March 13, 2014 